\title{
CD56 and CD3 expression in the liver and spleen of dogs with visceral leishmaniasis
}

\author{
Pamela Rodrigues Reina Moreira $^{1 *}$, Paulo Henrique Leal Bertolo ${ }^{2}$ and Rosemeri de Oliveira Vasconcelos ${ }^{2}$ \\ ${ }^{1}$ Postgraduate Veterinary Medicine Program, FCAV/UNESP (Faculdade de Ciências Agrárias e Veterinárias - Univ. Estadual Paulista), Via de Acesso Prof. Paulo \\ Donato Castellane, s/n, Jaboticabal, São Paulo, Brazil \\ ${ }^{2}$ Department of Veterinary Pathology, FCAV/UNESP, Jaboticabal, São Paulo, Brazil
}

\begin{abstract}
NKT cells are a subpopulation of lymphocytes with NK cell (CD56+) and T lymphocytes (CD3+) characteristics. These cells may to exterminate the infected cells and play an essential role in innate immunity. The objective of the present study was, through the immune histo-chemical technique, to analyze the livers and spleens of dogs with VL, considering the presence of parasites, CD56 and CD3 imuno detection. A total of 71 naturally infected dogs (infected group) from an endemic area for VL was used. A control group $(\mathrm{C}=10)$ was obtained from a not endemic area for VL. In the parasite load analysis, both liver and spleen showed no significant difference in the infected dogs. The immune detection of $\mathrm{CD} 56$ was low and not differ between the infected and control groups $(\mathrm{P}=0.7787)$ in liver. However, in spleen there were significant differences $(\mathrm{P}=0.0385)$ between infected (median=3.40) and control groups (median=13.70). CD3 showed significant differences in the liver $(\mathrm{P}=0.0229)$ of the infected (median=42.40) and control (median=7.90). In spleen these difference occurred between $(\mathrm{P}=0.0081)$ infected (median=51.0) and control groups too (median=381.0). Thus, we suggest that in the spleen and liver of infected dogs, the expression of CD56 and CD3 cells did not play a cytotoxic effect on parasitized macrophages in infected dogs. The proportion of CD56+ and CD3+ phenotypes was low in the infected group, suggesting that this cytotoxic way seems not to be efficiently activated in dogs with VL, regardless of the parasite load of each organ.
\end{abstract}

\section{Introduction}

In addition to macrophages, NK cells (innate immunity), can play an important role in defending hosts against injuries. These cells are cytotoxic lymphocytes that fight viral infections and tumors, without the need for previous recognition of a specific antigen [1].

NK cells have receptors for CD56 in their cytoplasmic membrane and have no expression of CD3 [1,2]. A small population of $\mathrm{T}$ lymphocytes also express markers that are found on NK cells, such as CD56, and are known as NKT cells, which regulate the immune response. NKT cells are a subset of lymphocytes that presenting NK cell and $\mathrm{T}$ cells (CD56+ CD3+) characteristics, that perform both cell functions in innate immunity and in the adaptive response. Probably these cells represent a primitive form and conserved immunity $[3,4]$. These NKT cells are capable of produce cytokines, such as IL-4 and IFN- $\gamma$, contributing to the host defense against pathogens [5]. Cells that just express CD56 and do not express CD3, are called natural killer cells, that secrete IL-2, IL-12, TNF- $\alpha$ and IFN- $\gamma$ and stimulating the cytotoxic action and destroying the infected cells, through of an increased expression of Fas ligand that activates apoptosis [6].

NK cells also induce target cell death by the release of granules and of cytotoxic proteins, that induce o Fas ligand to apoptosis, that is, they do not destroy microorganisms directly, but act on infected or neoplastic cells, through mechanisms similar to the mechanisms of CD8 T lymphocytes, through degranulation and release of enzymes that activate apoptosis of target cells $[1,2,6]$.

Thus, the objective of the present study was to evaluate the presence of CD56 and CD3 in the spleen and liver of dogs with VL and compare these findings with the density of parasitized macrophages in dogs with VL.

\section{Material and methods}

\section{Material}

The dogs used in this study were originated from the Zoonosis Control Center (Araçatuba, São Paulo State, Brazil), an endemic area for canine VL $[7,8]$. Seventy-one Leishmania infantum - infected dogs were used, without preference for age, breed or sex. The dogs were euthanazied according to decree number 51.838 of the Brazilian Ministry of Health and Resolution number 714, of June 20, 2002, of the Federal Veterinary Medicine Council. Necropsy was performed immediately after the dogs' death. The control group consisted of ten dogs from non-endemic area for VL [9], free of systemic pathological processes, such as systemic infection or cancer.

Infected and control dogs were selected, following confirmation or not of VL, by RIFI and ELISA and the presence or absence of the parasite DNA was confirmed by means of RT-PCR.

Liver and spleen fragments were collected and fixed in $10 \%$ formalin solution, for the immunohistochemical analysis, where we evaluated the immunostaining of CD56, CD3 and parasite load.

Correspondence to: Pamela Rodrigues Reina Moreira, FCAV/UNESP (Faculdade de Ciências Agrárias e Veterinárias - Univ. Estadual Paulista), Via de Acesso Prof. Paulo Donato Castellane, s/n, Jaboticabal, São Paulo, Brazil, Tel: 55-16-3209-7368, E-mail: pamela_rreina@yahoo.com.br

Key words: innate immunity, Leishmania infantum, compartmentalized immune response.

Received: April 18, 2017; Accepted: May 19, 2017; Published: May 23, 2017 


\section{Immunohistochemical analysis}

For immunodetection of the CD56 (monoclonal mouse, BIOCARE, catalog number CM164C) was made in the dilution of 1:75, with two hours of incubation at room temperature. To CD3 antibody (Mouse monoclonal, Dako, código M7254) was made dilution of 1:200. The immunodetection of amastigote forms of $L$. infantum, a hyperimmune serum from a dog positive was used (titer of 1:40,000), diluted at 1:1000, with 18 hours of incubation at $4^{\circ} \mathrm{C}$ [10]. The antigen recovery system was heat-induced (Pascal Pressure Chamber, DakoCytomation, Carpinteria, USA) with $10 \mathrm{mM}$ sodium citrate solution ( $\mathrm{pH}$ 6.0). The blocking of the endogenous peroxidase was performed with a $8 \%$ methanol and hydrogen peroxide solution, for 30 minutes. To block nonspecific reactions, a commercial product was used (Protein Block, DakoCytomation, catalog number X0909, Carpinteria, USA), for 30 minutes of incubation. The secondary complex used was a polymer complex bonded to peroxidase (Advance HRP ${ }^{\circledR}$ kit, DakoCytomation, catalog number K406889-2, Carpinteria, USA) and the chromogen was diaminobenzidine (DAB; DakoCytomation, catalog number K3468, Carpinteria, USA). The counterstaining of the sections was performed using Harris hematoxylin (Synth).

Negative controls were produced using the antibody diluent (Dako Cytomation, reference S302283-2) replacing the primary antibody. Positive controls were produced using tissues suggested by the manufacturer of each antibody.

To determine the number of immunostained cells, five microscope fields were analysed (Nikon Eclipse E200) with a 40x objective lens [7], which presented an area of approximately $0.19625 \mathrm{~mm} 2$. From the values obtained in these fields, an average number of immunostained cells was determined for each group (Leishmania infected and negative controls).

Statistical analysis was carried out using the nonparametric Mann Whitney test, with comparisons between the groups of dogs (infected and control) for immunostaining cells. The correlations between each variable in each organ of the infected group were determined using Spearman's correlation coefficient. The GraphPad Prism statistical software (version 4.00, 2003) was used for all the analyses, and differences were taken to be significant when $\mathrm{P}<0.05$.

\section{Results}

Immunostaining of CD56 was observed in the cytoplasm of cells and it presented a predominantly granular appearance. In the liver, these cells were discretely present within the portal, centrilobular and intralobular inflammatory infiltrates (Figure 1A). In the spleen, these cells occurred at a higher proportion in the red pulp and discretely in the white pulp (Figure 1B).

In the liver, the density of CD56 (Figure 2A) did not differ between the infected and control groups $(\mathrm{P}=0.7787)$. In turn, in the spleen (Figure $2 \mathrm{~B})$, the differences ( $\mathrm{P}=0.0385$ ) occurred between the infected $($ median $=3.40)$ and control groups $($ median $=13.70)$.

The detection of CD3 was observed in the cytoplasmic membrane of the lymphocytes. In the liver (Figure 1C) they were present in the sinusoids and in inflammatory infiltrate and in spleen (Figure 1D), it was predominantly in the white pulp and discretely in the red pulp.

In the liver (Figure $2 \mathrm{C}$ ) there was significant difference in the detection of CD3 $(\mathrm{P}=0.0229)$, where the infected dogs (median $=$ $42.40)$ and the control group (median $=7.90)$. Spleen $(\mathrm{P}=0.0081 /$

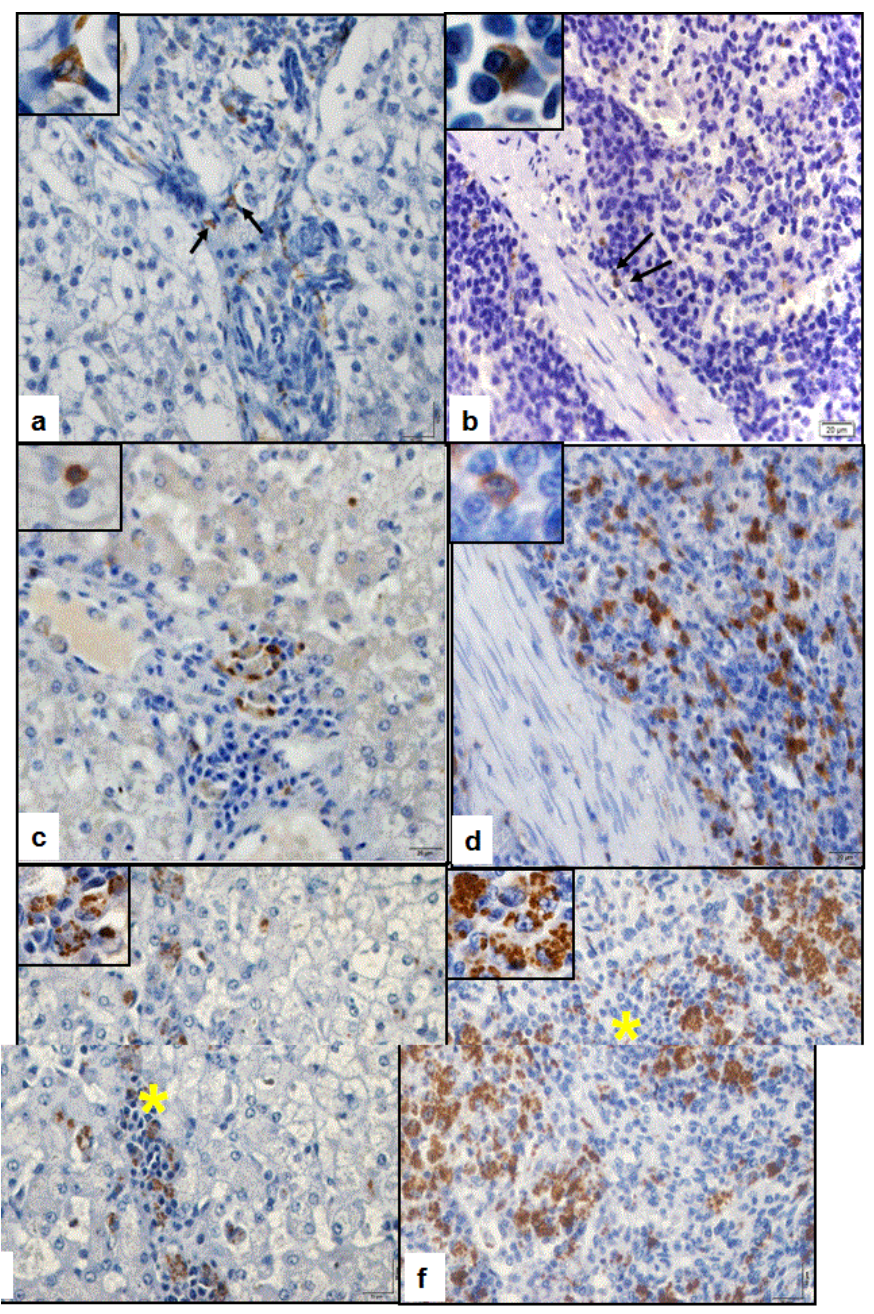

Figure 1. Photomicrograph of the immunodetection of CD56, CD3 and amastigote forms of Leishmania infantum in dogs with visceral leishmaniasis. (a) Note the discrete presence of CD56 expression in the hepatic inflammatory infiltrate (arrows). Inset shows cytoplasmic staining of CD56. (b) CD56 expression present in the red pulp of the spleen (arrows; inset). (c) Note the presence de CD3 in the hepatic inflammatory infiltrate and note the immunostaining in cytoplasmic membrane (inset). (d) CD3 expression in lymphocytes of the red pulp splenic. (e) Staining of amastigote forms of the parasite in the cytoplasm of macrophages present in the hepatic inflammatory infiltrate (*/inset). (f) Presence of L. infantum in macrophages of the splenic granulomas of the red pulp $(* /$ inset). Polymer complex bonding to peroxidase; $40 \mathrm{x}$ objective lens and 100x objective lens to insets.

Figure 2D) the significant differences appeared between the infected $($ median $=51.00)$ and control groups $($ median $=381.00)$.

Immunostaining of amastigote forms of Leishmania infantum was observed in the cytoplasm of macrophages present in the hepatic infiltrate (Figure 1E) and in the splenic granulomas of the red pulp (Figure 1F) in infected dogs.

In analyzing the parasite load, both in the liver $(\mathrm{P}=0.1041$; median $=$ $1.20)$ and in the spleen $(P=0.2141$; median $=2.90)$, there was no significant difference in these organs between the groups of infected dogs.

Among the correlations of all variables, was only observed an association between CD3 and CD56 in the spleen, with a weak positive correlation $(\mathrm{P}=0.009 ; \mathrm{r}=0.307)$.

\section{Discussion}

There was no significant difference between liver as in the spleen 
a
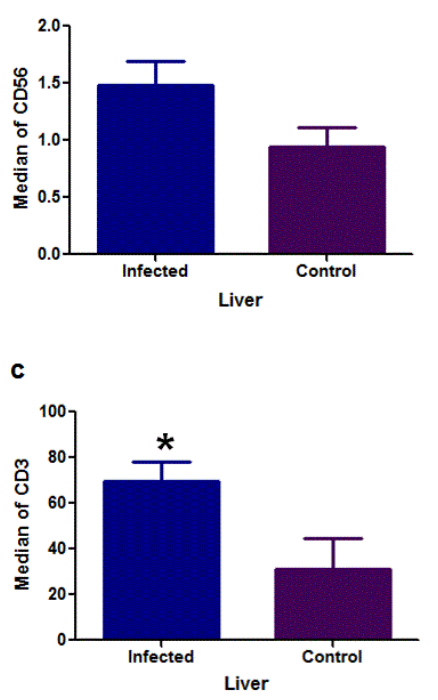

b

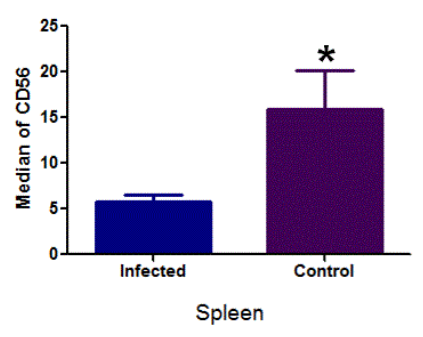

d

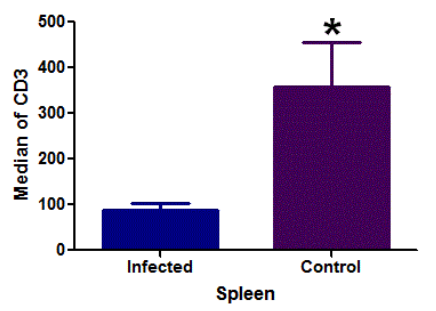

Figure 2. Median of immunostaining of CD56 and CD3 in infected dogs and control groups, in the liver and spleen. (a) In the liver the CD56 expression, did not differ between the infected and control groups $(\mathrm{P}=0.7787)$. (b) Note the significant difference to CD56 expression in the spleen $(\mathrm{P}=0.0385)$, between the infected and control groups. (c/d) Note the significant difference of the variable CD3 in the liver $(P=0.0229)$ and in the spleen $(P$ $=0.0081)$. Mann-Whitney nonparametric tests, ${ }^{*}(\mathrm{P}<0.05)$.

for parasitized cells, although the spleen presented a higher proportion of parasitized macrophages. In mice, Leishmania sp. was detected in early stages of infection in the liver and later in the spleen, and it was suggested that these differences were related to a different profile of these cell in each organ [11].

Cytotoxicity and CD56 expression are characteristics acquired by NK cells [12]. In VL, NK cells act efficiently towards destroying the parasite $[11,13]$. However, in the present study, both the organs (liver and spleen) showed low immunodetection of CD56. However, in spleen these immunodetectin was even lower in infected dogs. Therefore, these cells seem not to have any effective participation in infected dogs, possibly due to the imbalance in the profile of Th1 and Th2 cytokines, which has already been described in dogs with VL [14-16].

In the liver of the present study, the density of CD3 was high in infected dogs when compared to the control group. It has been reported that the liver's ability to resolve the infection is dependent on the formation of inflammatory foci around infected Kupffer cells, composed of lymphocytes and monocytes, which allow the fusion of infected cells and the destruction of amastigotes by activated macrophages in infiltrate, leaving resistant to infection [11].

Bogdan (2012) observed in experimental mouse models that NK cells are not essential for resolving cutaneous and visceral leishmaniasis, although there is evidence that these cells present a protective function in mice with cutaneous leishmaniasis [17]. This is mainly based on activation of IFN- $\gamma$, mediated by macrophages (Th1 response). In the spleen of the present study, the detection of CD56 was low in the infected dogs and they had high splenic parasitism. In mice with multiple sclerosis has been described that NKT cells may exert a protective role or pathogenic, depending on the cytokines that they secrete. If the NKTs cells are activated concomitantly with the infection, its action is pathogenic, due to IL-4 secretion [18]. In the present study, probably the cells which express CD56 in infected dogs may be secreting cytokines that promote the growth and multiplication

of the parasite.

In the present study, possibly the cytotoxic activity of CD56 expression was ineffective in liver and spleen, as was also observed in experimental infection with $L$. donovani in mice. It was observed that resolution of the infection in spleen is inefficient, because it seems to involve a failure of T lymphocytes and NK cells, of activating macrophages in the marginal zone efficiently. This could result in a failure of these cells to produce cytokines that stimulate the leukocyte migration (INF- $\gamma$, TNF- $\alpha$, IL-2 and IL12) or failure of infected macrophages of activating the intrinsic mechanisms by means of IL-12 neutralization [11].

The mechanisms through which NK cells recognize target cells have not yet been characterized, because their cell receptors remain incompletely identified and because each NK cell probably expresses several different receptors. Some are able to secrete cytokines and translate positive signals (cytotoxicity), and others activate inhibitory signals, such as, protection against lysis of healthy cells $[13,19]$. In future studies, it would be of interest to evaluate the expression of the different receptors of these cells in dogs with VL, because perhaps only the inhibitory receptors are activated, thereby preventing cytotoxic action by NK cells $[20,21]$

\section{Conclusions}

Thus, we suggest that in the spleen and liver, the detection of CD56 and CD3 did not play any apparent cytotoxic role in relation to macrophages parasitized in infected dogs, leaving to parasite multiplication.

\section{Ethical standards}

The design for this study was approved by the Ethics and Animal Welfare Committee (CEUA no. 000599-08) of FCAV/UNESP, Jaboticabal, State of São Paulo, Brazil.

\section{Acknowledgements}

Financial assistance was provided by FAPESP (Fundação de Amparo à Pesquisa do Estado de São Paulo; no. 2009/07815-4). P.R.R. Moreira was supported by a grant from FAPESP (no. 2009/157367). The authors wish to acknowledge Mrs. F.A. Ardisson for her histotechnical assistance.

\section{Conflict of interest}

The authors declare that they have no conflict of interest.

\section{References}

1. Luo DZ, Vermijlen D, Ahishali B, Triantis V, Plakoutsi G, et al. (2000) On the cell biology of pit cells, the liver-specific NK cells. World J Gastroenterol 6: 1-11. [Crossref]

2. Korbel DS, Finney OC, Riley EM (2004) Invited review: Natural killer cells and innate immunity to protozoan pathogens. Int. J. Parasitol 34: 1517-1528. [Crossref]

3. Khvedelidze M, Chkhartishvili N, Abashidze L, Dzigua L, Tsertsvadze T (2008) Expansion of CD3/CD16/CD56 positive NKT cells in HIV/AIDS: the pilot study. Georgian Med News 165: 78-83. [Crossref]

4. Mesquita Júnior D, AraújoJAP, Catelan TTT, Souza AWS, Cruvinel WM, et al. (2010) Sistema Imunitário - Parte II Fundamentos da resposta imunológica mediada por linfócitos T e B. Rev. Bras. Reumatol 50: 552-580.

5. Abbas A.K., Lichtman A.H, Pillai, S. 2015. Imunologia Celular e molecular (8ed.). Rio de Janeiro: Elsevier, p.228-229.

6. Zhang Q, Liu XY, Zhang T, Zhang XF, Zhao L, et al. (2015) The dual-functiona capability of cytokine-induced killer cells and application in tumor immunology. 


\section{Human Immunol 76: 385-391. [Crossref]}

7. Moreira PR, Vieira LM, de Andrade MM, de Barros Bandarra M, Machado GF, et al (2010) Immune response pattern of the popliteal lymph nodes of dogs with visceral leishmaniasis. Parasitol Res 107: 605-613. [Crossref]

8. Moreira PRR, Bandarra MB, Magalhães GM, Munari DP, Prandini MM, et al. (2013) Influence of apoptosis on the cutaneous and peripheral lymph node inflammatory response in dogs with visceral leishmaniasis. Vet Parasitol 192: 149-157.

9. Oliveira TM, Furuta PI, de Carvalho D, Machado RZ (2008) A study of cross-reactivity in serum samples from dogs positive for Leishmania sp, Babesia canis and Ehrlichia canis in enzyme-linked immunosorbent assay and indirect fluorescent antibody test. Rev Bras Parasitol Vet 17: 7-11. [Crossref]

10. Tafuri WL, Santos RL, Arantes RM, Gonçalves R, de Melo MN, et al. (2004) An alternative Immunohistochemical method for detecting Leishmania amastigotes in paraffin-embedded canine tissues. J Immunol Methods 292: 17-23. [Crossref]

11. Engwerda CR, Kaye PM (2000) Organ-specific immune responses associated with infectious disease. Immunol Today 21: 73-78. [Crossref]

12. Shivam P, Kumari S, Jamal F, Kumar V, Kumar M (2015) Leishmania donovani skews the CD56+ Natural Killer T cell response during human visceral leishmaniasis. Cytokine 73: 53-60. [Crossref]

13. Scott P, Trinchieri G (1995) The role of natural killer cells in host-parasite interactions. Curr Opin Immunol 7: 34-40.
14. Barbiéri CL (2006) Immunology of canine leishmaniasis. Parasite Immunol 28: 329 337. [Crossref]

15. Corrêa AP, Dossi AC, de Oliveira Vasconcelos R, Munari DP, de Lima VM (2007) Evaluation of transformation growth factor- $\beta 1$. interleukin-10, and interferon-? in male symptomatic and asymptomatic dogs naturally infected by Leishmania (Leishmania) chagasi. Vet Parasitol 143: 267-274. [Crossref]

16. Alves CF, de Amorim IF, Moura EP, Ribeiro RR, Alves CF, et al. (2009) Expression of IFN-? TNF-a, IL-10 and TGF- $\beta$ in lymph nodes associates with parasite load and clinical form of disease in dogs naturally infected with Leishmania (Leishmania) chagasi. Vet Immunol Immunopathol 128: 349-358. [Crossref]

17. Bogdan C (2012) Natural killer cells in experimental and human leishmaniasis. Fron Cell Infect Microbiol 2: 69. [Crossref]

18. Jahng AW, Maricic I, Pederson B, Burdin N, Naidenko O, et al. (2001) Activation of natural killer $\mathrm{T}$ cells potentiates or prevents experimental autoimmune encephalomyelitis. J Exp Med 194: 1789-1799.

19. Murphy K, Travers P, Walport M (2008) Janeway's Immunobiology (7ed.). New York: Garland Science, p.887.

20. Halloran PF, Wadgymar A, Autenried P (1986) The regulation of expression of major histocompatibility complex products. Transplantation 41: 413-420. [Crossref]

Copyright: $\odot 2017$ Moreira PRR. This is an open-access article distributed under the terms of the Creative Commons Attribution License, which permits unrestricted use, distribution, and reproduction in any medium, provided the original author and source are credited. 